\title{
CODEBOOK FOR ANALYZING CONTENT AND FUNCTION OF COMMUNICATION IN SOCIAL-ECOLOGICAL DILEMMA EXPERIMENTS
}

\author{
Daniel A. DeCaro* \\ Version 1.0 (January 6, 2021)
}

\begin{abstract}
This codebook provides concepts and methodologies for coding and quantifying the content and function of communication in group social dilemma experiments, specifically with a social and ecological component (e.g., common pool resource dilemma). The content that is coded pertains to such categories as small talk, humor, information exchange (e.g., ecological, social, institutional), enforcement (e.g., praise, warnings, threats), decision making (e.g., proposals, choosing). Functional categories pertain to key functions needed for group members to govern the dilemma: e.g., develop agreements, make group decisions (e.g., democratic decision making), resolve conflicts, and enforce compliance. This codebook provides guidance for metrics to associate coded communication content and function to observed cooperation.
\end{abstract}

\section{Acknowledgements}

This material is based upon work supported by the National Science Foundation under Grant No. 1658608. Any opinions, findings, and conclusions or recommendations expressed in this material are those of the author(s) and do not necessarily reflect the views of the National Science Foundation. The author wishes to thank Marci S. DeCaro (University of Louisville) and Lianda Velic (University of Louisville) for the feedback and help in developing this work.

*Affiliation: University of Louisville, Email: daniel.decaro@louisville.edu 


\section{TABLE OF CONTENTS}

EXECUTIVE SUMMARY

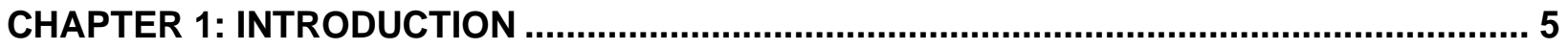

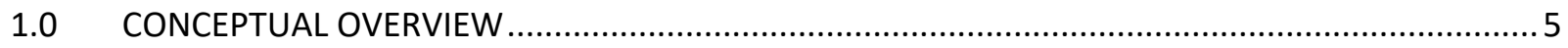

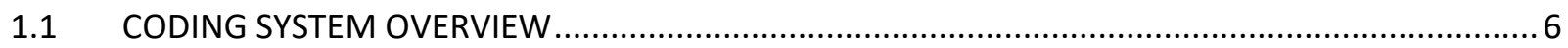

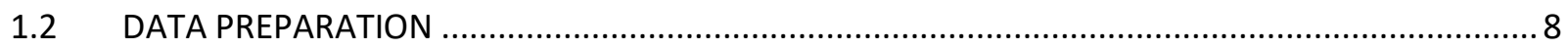

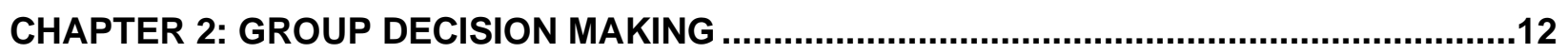

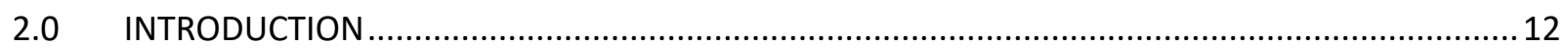

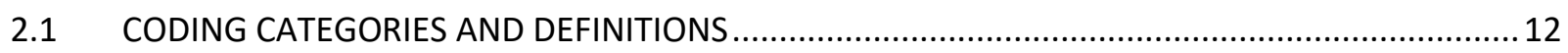

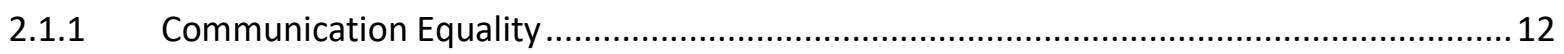

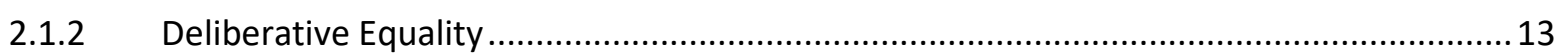

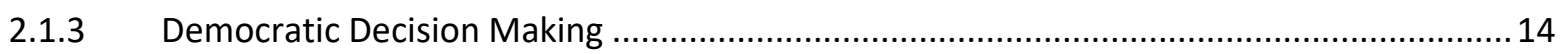

CHAPTER 3: ENFORCEMENT

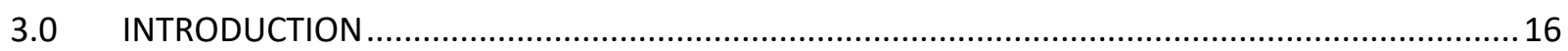

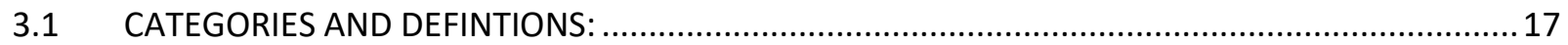

3.1.2 Praise and Encouragement [PRAISE] ……………......................................................

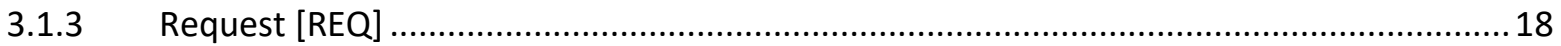

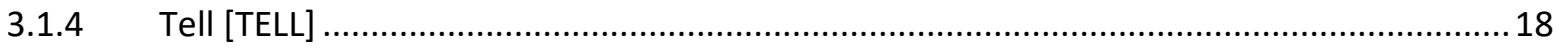

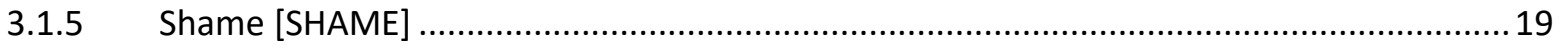

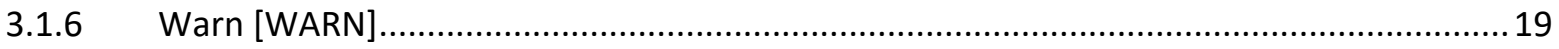

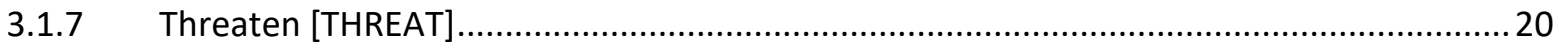

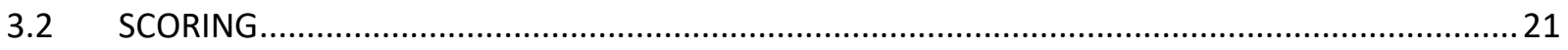

CHAPTER 4: CODING TOPICAL CONTENT

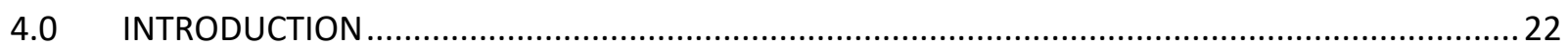

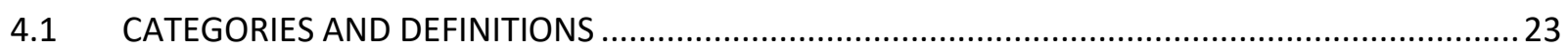

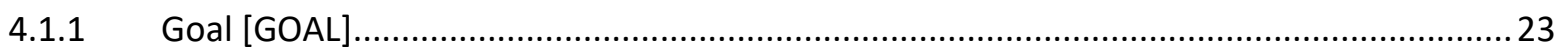

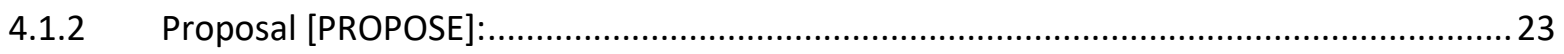

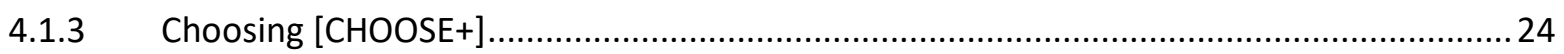

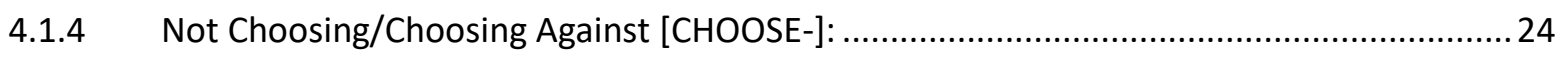

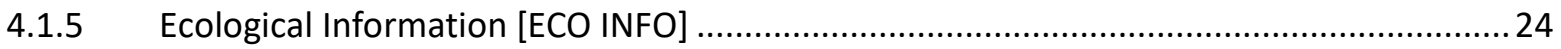

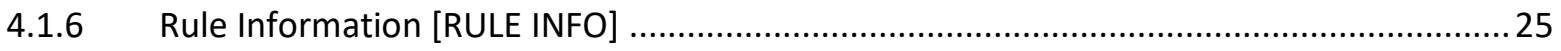

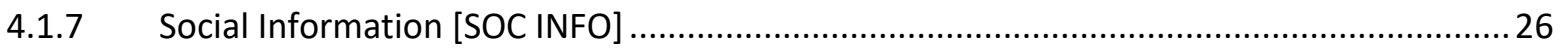

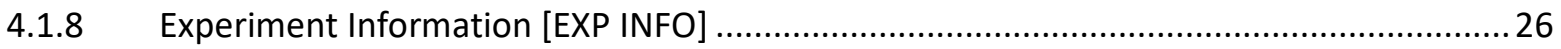

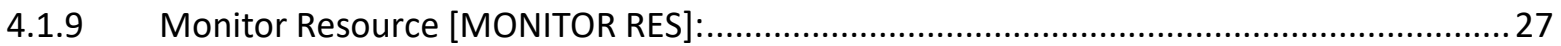

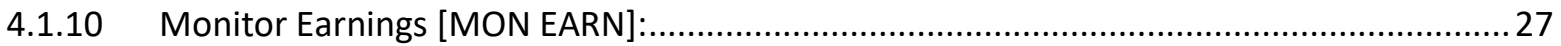




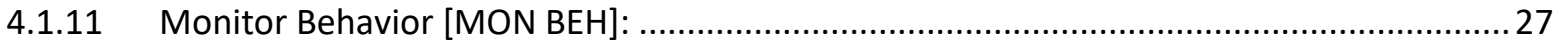

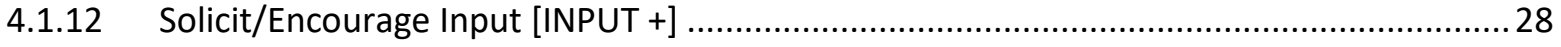

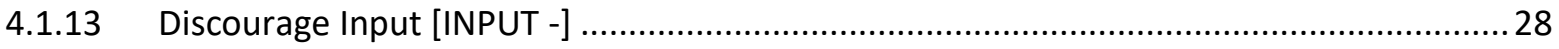

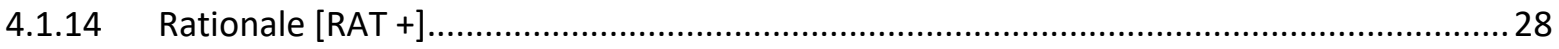

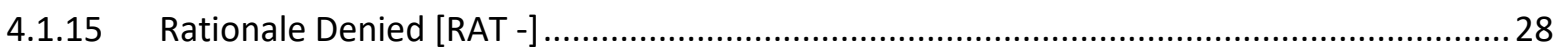

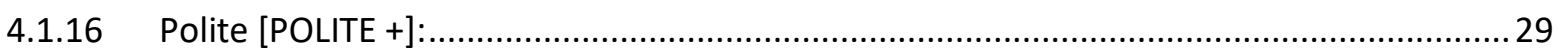

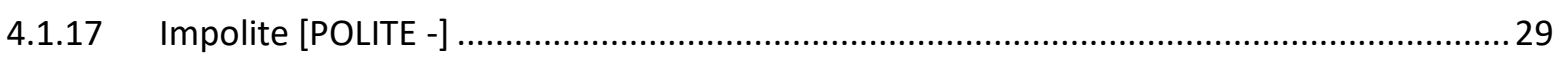

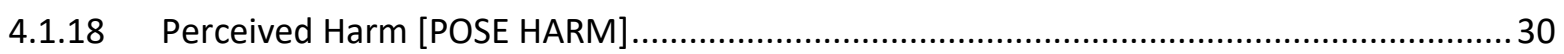

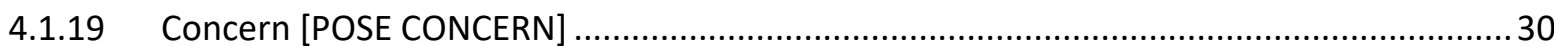

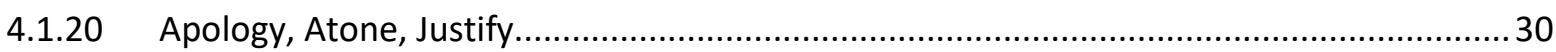

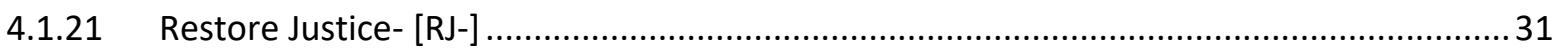

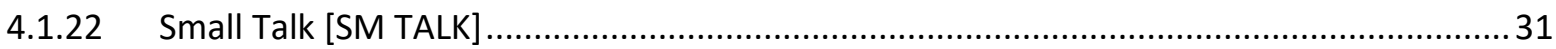

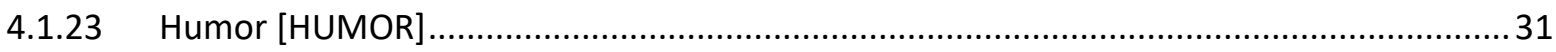

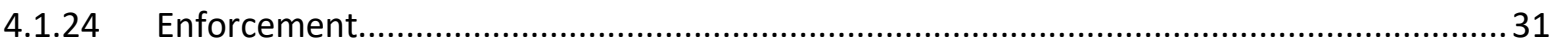

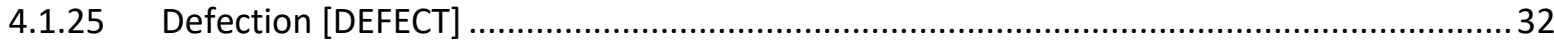

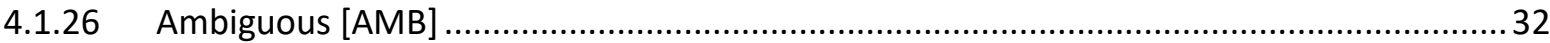

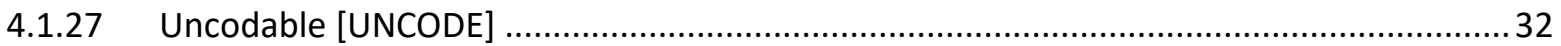

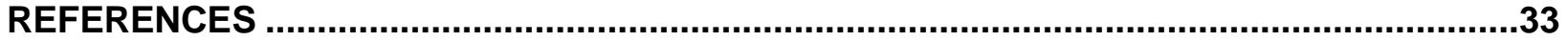




\section{Project:}

This codebook is a product of a larger research project with Co-PIs Marco A. Janssen, and Allen Lee, funded by the National Science Foundation:

Psychosocial, motivational, and cooperative effects of communication, enforcement, and participatory decision making in resource dilemmas. (2017-2022). National Science Foundation (NSF): Decision, Risk \& Management Sciences (Award \#1658608)

\section{Work in Progress:}

This is a work in progress. Subsequent versions developed by the author will be published on a rolling basis, as needed to address new experiments and observations.

\section{Recommended Coder Expertise:}

This coding system assumes that coders are familiar with economic rational choice theory, common-pool resource and public good dilemmas (e.g., Ostrom 1990), and the specific experimental task, Foraging Task (see Jassen 2010, Janssen et al. 2010). This background knowledge is required to code effectively and understand the contextual meaning of participants' communication and behavior. 


\subsection{CONCEPTUAL OVERVIEW}

This coding system starts with the recognition that the primary target of the investigation is problem-solving and governance in a social-ecological dilemma. Thus, communication is analyzed in light of, and in service of, problem-solving/governance in a social dilemma.

\section{Groups Must Solve Two Fundamental Problems (Dilemmas):}

(1) Managing/sustaining the shared resource (resource management), to improve individual and collective earnings (CPR Dilemma). First Order Dilemma (Appropriation).

(2) Managing each other (i.e., governing) to encourage and sustain coordination and compliance (i.e., cooperation): this entails creating social order and institutions (i.e., rules, agreements, and social norms) to guide behavior (Public Good Dilemma:

creating a governance system and social order). Second Order Dilemma (Provision).

The CPR Dilemma generally cannot be reliably (robustly) solved until the Public Good Dilemma of provisioning a viable governance system (governance dilemma) is resolved (see Ostrom 1990: 38-39 "interdependence, independent action, and collective action," 42-50 "three puzzles: supply, commitment, and monitoring"; cf. Gardner et al. 1990).

\section{These Dilemmas Pose Several Important Challenges:}

\section{Governance Dilemma}

Individuals need to collectively create a system of rules, agreements, and norms to coordinate their behavior and improve resource management (problem of supply); they also need to find ways to create credible commitment to those governance systems to compel and bolster coordination and compliance (problem of commitment); they also need to monitor behavior, and enforce their rules and agreements (problem of monitoring and enforcement). Governance systems may need to be updated and improved iteratively to address complex patterns of behavior and new developments in the social-ecological system; this may include implicit or explicit experimentation to find effective solutions (adaptive governance).

\section{CPR Dilemma}

Individuals, and their groups, need to understand the critical ecological features, processes, and dynamics of the resource system and larger ecological system, in order to devise effective management techniques (i.e., rules, procedures, strategies). They may need to adjust these solutions over time, or experiment with new techniques to probe underlying ecological features and improve their management solutions (adaptive management). 


\subsection{CODING SYSTEM OVERVIEW}

Our coding system analyzes communication in terms of multiple levels of abstraction, or complexity: coding the intended function or purpose of communication (e.g., democratic decision making, enforcement) and coding how frequently particular topics are discussed (e.g., ecological information, small talk). The reason we code in terms of both function and frequency of topical content is to capture the greatest descriptive and explanatory range of information from the group communication. In addition, topical content frequency coding is more widely used in prior research, but has yielded only limited explanatory power for understanding cooperation (e.g., Janssen 2010, Pavitt 2011). We use both methodologies to refine them and investigate their potential scientific contributions (cf. Brauner, 2018).

\section{CODING FUNCTION:}

Coding for function means that communication content and patterns are examined in terms of their apparent or hypothesized functional or psychological significance (i.e., intended purpose, meaning) (cf. Deci and Ryan 1987; Tschan et al. 2018) specifically for addressing the core dilemmas and challenges posed by the governance and problem-solving tasks inherent to collective management of the social-ecological dilemma. This approach is beneficial because it identifies how individuals are conceptualizing the governance task and social-ecological dilemma, and how individuals interact with each other in a group setting (cf. Pavitt 2011).

This approach contrasts with most previous coding systems, which have primarily focused on counting the frequency of particular types of topical content that were communicated (e.g. the number of statements about ecological information), without determining the context of those statements or their intent or purpose (e.g., goals that individuals/groups were trying to accomplish when sharing ecological information). Some researchers have coded communication in social dilemmas in terms of functional categories (e.g., Pavitt 2011, Janssen 2010). Our approach builds on those prior attempts by focusing on democratic decision making processes within the group and specific governance tasks thought to be fundamental to successful governance in social dilemmas (i.e., Gardner et al. 1990, Ostrom 1990). We also further refine previous functional coding categories by differentiating different types within each category (e.g., distinguishing between different types of enforcement, rather than coding all types of enforcement as a single "enforcement" category).

Our coding scheme consists of three functional categories (see later sections for details):

- Fair Decision Making (Procedural Justice, Autonomy-Support). Identify critical decision-making events. Determine the type of decision-making strategies (e.g., unilateral, majority rule, consensus), and the corresponding level of shared (democratic) decision making, typically used to make decisions about conservation agreements, enforcement, and other important governance tasks. In addition, determine the extent to which communication is being shared equally by group members.

- Enforcement. Identify the specific types of enforcement and reward strategies groups use to encourage and compel short- and long-term cooperation and compliance. These include such strategies as negative social sanctions (e.g., warnings, threats) and positive social sanctions (e.g., praise and encouragement).

- Conservation Agreements. Identify the specific conservation strategies or agreements developed by the group to manage the common-pool resource. 


\section{CODING TOPICAL CONTENT:}

In addition to coding overall segments of communication in terms of the functional categories outlined above, we code the number of times particular information (topical content) is communicated. This type of coding, which focuses on frequency of content, does not necessarily capture the underlying intent or functions contained in a dialogue. Coding topical content-line-by-line dissects larger segments of dialogue into fragments (e.g., breaks up decision events consisting of multiple statements). However, topical content coding is the most common method of communication coding in the few social dilemma experiments that have coded communication (Pavitt 2011, Janssen 2010, Janssen et al. 2010). In addition, coding the frequency that particular topics are discussed provides a basic description of communication patterns (Brauner 2008) and could potentially be associated with cooperation, though prior experiments have generally found little such relationship.

We identify 27 topical categories (in addition to 7 enforcement categories):

1. Goal

2. Proposal

Discussing goals.

3. Choose

Proposing potential conservation strategies and other solutions.

4. Choose Voicing acceptance ("choice") among proposals (i.e., "choosing").

5. Eco Info Voicing rejection of proposals.

6. Rule Info

Discussing ecological information (e.g., token dynamics).

7. Soc Info

Clarifying aspects of chosen agreements and strategies.

8. Exp Info Discussing information about beliefs, motivations, behavior.

9. Mon Res Discussing information about the experiment itself.

Monitoring (e.g., reporting) resource pool levels.

10. Mon Earnings Monitoring earnings (e.g., reporting a person's earnings during a round).

11. Mon Beh

12. Input Monitoring someone's actions (without evaluating or enforcing).

13 Input Actively requesting or encouraging input into the discussion.

14. Rat Actively discouraging input into the discussion.

15. Rat Providing a rationale or justification

16. Polite Actively discouraging or withholding a rationale/justification.

17. Polite Deliberate attempts to be polite (e.g., greetings, thanking).

18. Pose Harm Deliberate attempts to be impolite (e.g., interrupting on purpose).

19. Pose Concern Voice a perceived concern (e.g., shortcoming in conservation strategy).

20. RJ Apology Apologize for a perceived harm.

21. RJ Atone Provide/agree to tangible atonement for a perceived harm.

22. RJ Justify

23. RJ Provide a rationale ("Rat") for a perceived harm.

24. Small Talk

25. Humor Any deliberate refusal to apologize, atone, or justify for a perceived harm.

26. Ambiguous Discussing non-task topics (e.g., popular events, personal interests).

27. Uncodeable Deliberate attempts to be silly or funny.

Too ambiguous to code reliably.

Statement is incomprehensible (e.g., illegible), or no category exists. 


\subsection{DATA PREPARATION}

Follow these steps to prepare the raw communication data for coding. Before coding can occur, each group's raw communication (chat) data must be organized into complete thought units, and then segmented and labeled into major events, such as decision events.

\section{Units of Analysis}

We distinguish between two units of analyses: thought units and events. The basic unit of analysis for topical content (i.e., topics discussed) is complete thoughts ("thought units"). A thought unit is typically synonymous with individual or discrete text lines in the computermediated chat. However, sometimes the components of a single thought will be broken up or spread across multiple lines. This is often due to the nature of communicating by written chat (i.e., participants cannot follow typical facial and verbal cues to pace their conversations). Participants may also intentionally divide a single thought across multiple lines (for clarity), or their communication may be accidentally interrupted by other participants as individuals communicate in parallel. The basic unit of analysis for functional coding (e.g., of democratic decision making) is the complete event (e.g., coding within decision events) (Reed 2018).

\section{Consolidate Thought Units}

The first step in data preparation is to identify broken thought units and combine them. When you consolidate broken thoughts, you may have to reorder lines to combine divided thought units into a single line. Note consolidated statements by including the timestamp immediately before the combined part.

$\begin{array}{lr}\text { Original } & \\ -332.277 & 4 \\ -331.921 & 2 \\ -326.141 & 3 \\ -323.588 & 4 \\ -320.191 & 2 \\ -319.037 & 3 \\ -314.386 & 4 \\ -306.146 & 4 \\ -298.912 & 4 \\ -298.22 & 2 \\ -291.178 & 4 \\ -287.12 & 4 \\ -282.123 & 3 \\ & \\ \text { Consolidated } \\ -332.277 & 4 \\ -331.921 & 2 \\ -314.386 & 4 \\ -298.912 & 4 \\ -320.191 & 2 \\ -326.141 & 3 \\ -298.22 & 2 \\ -282.123 & 3 \\ -291.178 & 4\end{array}$

Example

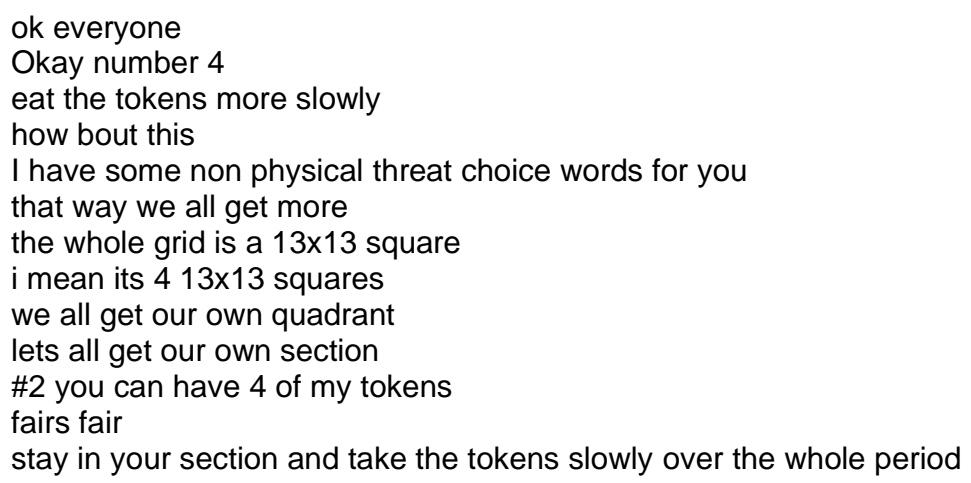




\title{
III. Number the Lines
}

\section{After you are certain you have correctly consolidated the broken thought units, number each line, for ease of reference.}

\author{
Example
}

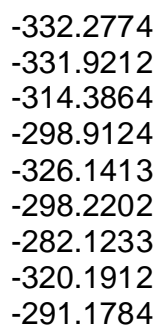

\section{Segment and Label Topics and Decision Events}

Segment the stream of communication into (a) meaningful topics and (b) decision events.

Meaningful Topics: Segmentation for meaningful topics occurs around natural transition points in communication, as group members introduce new ideas, topics, or tasks.

Decision Events: Decision events pertain to an important resource management or governance topic (e.g., solutions). They typically begin with a proposal (i.e., proposed solution, "Proposal"), perceived concern or injustice ("Pose Harm," "Pose Concern"), or other issue, and end when the group transitions to another topic, runs out of time (i.e., the dedicated chat period ends or round ends), or clearly chooses an option. You must rely on context to determine the end point.

\section{Identify all major decision events made by the group. Label each event, and record the line numbers.}

a) Divided Decision Events: A decision event may be spread (divided) across multiple speaking turns, thought units, or segments of dialogue within the same chat period or round. A particular decision event can be interrupted or set aside momentarily by the group and then revisited during the same chat period or round.

Note: A single decision event CANNOT be carried across multiple chat periods or rounds. Therefore, if a chat period or round ends, and group members later discuss the same or similar topic, this is automatically treated as a new decision event.

\section{Example}

Group 1 began Chat Period 1 with a decision event to decide their resource management strategy (Decision 1: Lines 1-7), and this was interrupted by a second decision event to determine how to deal with a perceived injustice (stolen tokens) raised by Player 2 (Decision 2: Lines 8-9). Afterward, the group returned to Decision 1 to further add to the proposed resource management strategy (Line 10), and that was again set aside to deal with another perceived injustice (stolen tokens) raised by Player 3 (Decision 3: Lines 11-16). The group then returned to Decision 1 and finalized that decision by choosing a private property rule (Lines 17-21). (See Fig. 1) 
Figure 1. Identifying and Segmenting Decision Events

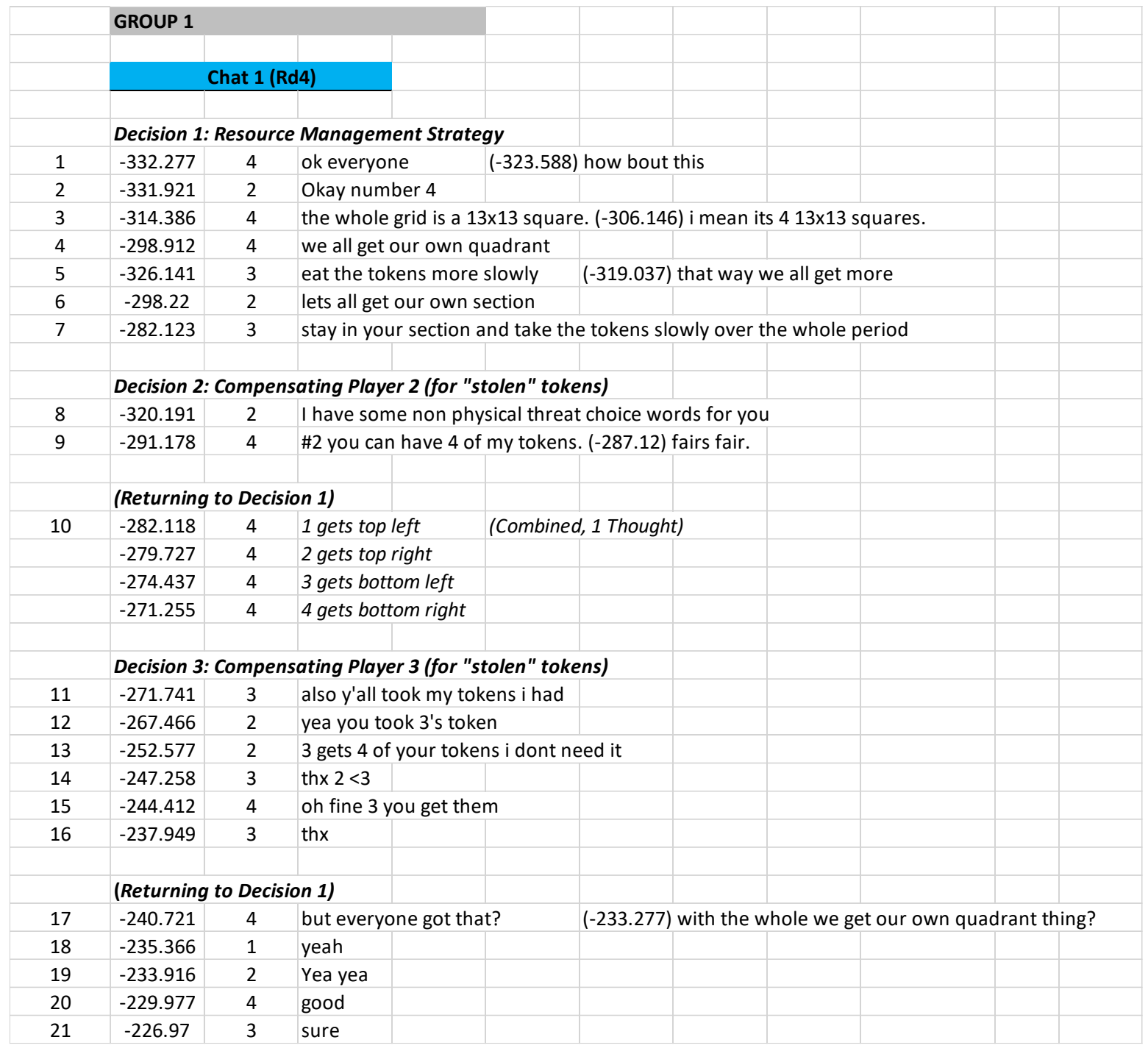

b) Revisiting a Decision: Sometimes groups will revisit the same decision topic, but do so in a way that starts a new decision event. This situation must be determined based on context and the apparent intention of the proposal or problem that triggered the event. A common example is when a group reopens a previously concluded decision to make a new decision about its rejection, revision, or re-approval.

\section{Example}

When Group 1 revisits Decision 1 (Figure 1), it is clear from context that they are intending to continue the ongoing dialogue about private property, and that a decision has not been reached until Line 21. These segments are not considered new or separate decision events. In contrast, in Group 3 (Figure 2), group members finalize a private property rule decision during Chat Period 1, at Line 24. They then test that strategy during Round 4. Afterward, during Chat Period 2, Players 2 and 3 ask if anything should be done differently (Lines 39-40), reopening their previous decision for revision/re-approval, triggering a new decision event (see Figure 2). 
Figure 2. New Decision Event (Reopening a Previously Concluded Decision)

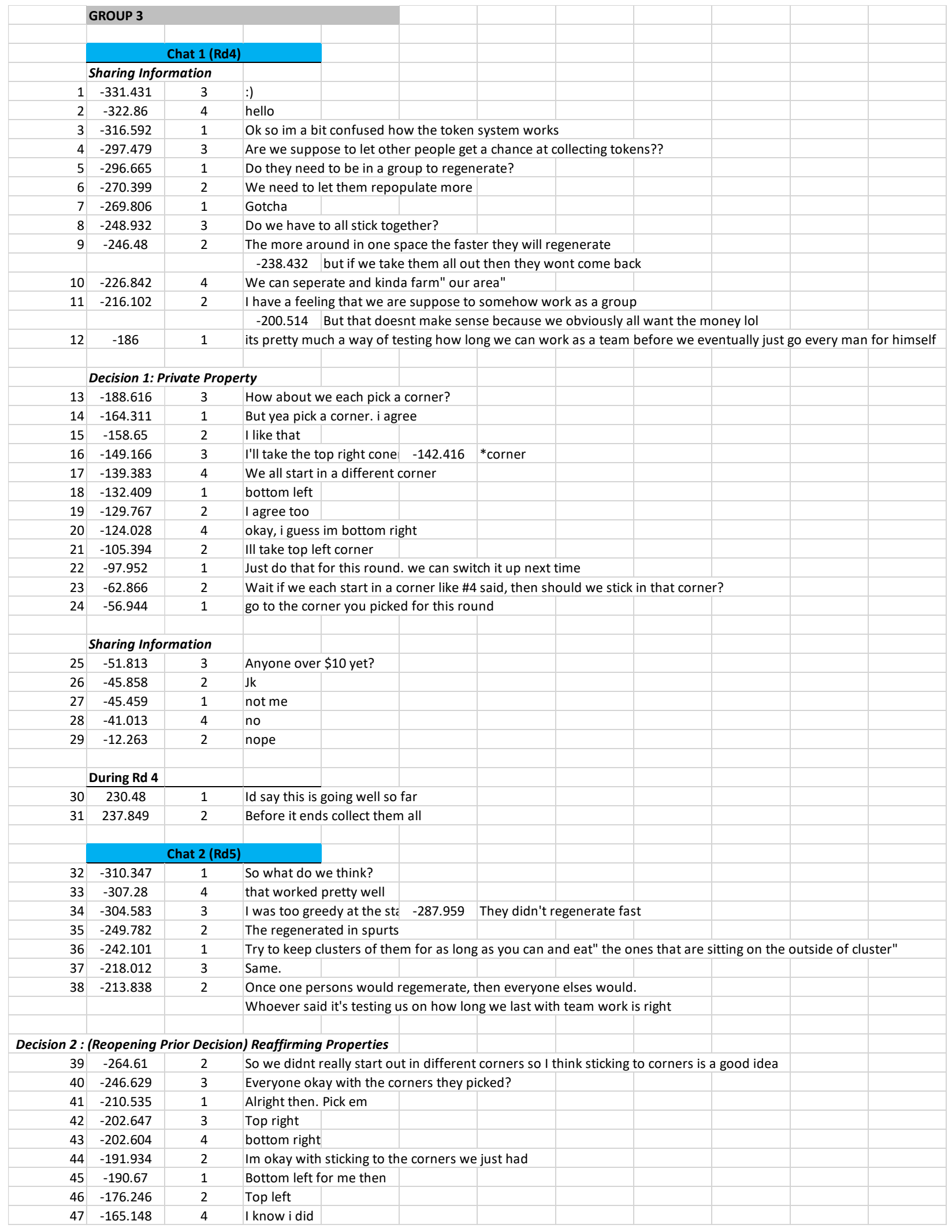




\subsection{INTRODUCTION}

Effective communication and decision making are central components of governance in a social dilemma (Ostrom 1990). Communication and decision making within a group, or governance, context can be classified as relatively fair and autonomy-supportive (facilitative), or unfair and controlling (coercive). This fairness can influence individual motivation and group cooperation (e.g., DeCaro et al. 2015). The current coding evaluates the fairness of group decision making in the social dilemma. We differentiate multiple dimensions of fairness and autonomy-support based on existing concepts and indicators from other domains (e.g., Colquitt 2001, Tyler 2006, Deci and Ryan 2000, 2017; see DeCaro et al. 2015, DeCaro 2019 for synthesis).

Vincent Ostrom $(1980,1994)$ distinguishes between two fundamental types of power. When group members attempt to forcefully control or dominate others-even for mutual or paternalistic benefit-they are exerting power over others. Generally, this will have the appearance of unilateral decision making by an individual, leader, or faction (i.e., minimal winning coalition), thereby restricting some members from participating fully in deliberation and institutional design (voice), institutional selection (choice), or both. In contrast, when group members endeavor to share power, making decisions inclusively, they are exercising power with each other. This type of power generally involves shared decision making and obedience to democratic processes, rather than to a leader or center of authority (DeCaro 2011).

This basic concept of power has been independently and meaningfully developed in other theoretical traditions, including controlling versus autonomy-supportive interpersonal and organizational environments (Ryan and Deci 2017), procedural justice in law and organizations (Tyler 1990, 2006), procedural utility (Frey et al. 2004), and directive versus facilitative organizational leadership (e.g., De Cremer and Tyler 2005). Our coding system is inspired by these theoretical traditions but is further informed by social cognition, behavioral economics, and theory of collective action; the system is also practically grounded in the study of social dilemmas (see DeCaro et al. 2015, DeCaro 2018, 2019).

We compute 3 potential indicators of fairness and autonomy-support based on prior research and theory: the extent to which (1) individuals communicate equally, (2) individuals communicate equally specifically during decisions, and (3) groups make decisions democratically, using inclusive group decision strategies.

\subsection{CODING CATEGORIES AND DEFINITIONS}

\subsubsection{Communication Equality}

Here, we focus on overall communication, in order to calculate an overall indicator of communication fairness, or equality. To do this, we use a method established by Janssen (2010) (see also, Rogat and Adam-Wiggins 2014:833).

\section{Gini Coefficient of Communication (Gini Comm):}

The Gini Coefficient is a method of quantifying the amount of inequality in a population. The Gini Coefficient is often used to calculate economic inequality (Lerman and Yitzhaki 1984). We use it to quantify the extent to which communication opportunity is shared equally among group 
members. The Gini coefficient ranges from 0 to 1 : Gini $=0.00$ represents perfect equality (all four group members communicate equally), whereas Gini $=1.00$ represents perfect inequality (a single person is the only one communicating). It has been proposed that this coefficient may be a general indicator of fairness and autonomy-support in group interaction (DeCaro 2019), and/or group liking and cohesion (Janssen 2010).

\section{Calculation:}

A. Count the total number of thought units ${ }^{1}$ contributed by each individual, across a group's entire communication (i.e., all of a group's communication/thought units).

B. Compute the Gini Coefficient. For simplicity, we entered the count values into the opensource calculator provided by Conrad (2007).

\subsubsection{Deliberative Equality}

The purpose of this section is to calculate the extent that individual group members contribute equally to deliberation and discussion of important decisions, as an indicator of fairness and autonomy-support during decision making (i.e., extent that individuals have or exercise equal opportunity to voice their opinions during decisions). Hence, this calculation isolates decisionspecific communication from other (i.e., overall) communication.

\section{Gini Coefficients:}

We calculate two versions: a standard version and an adjusted version.

The (standard) Gini Coefficient of Deliberation is computed based on the number of thought units contributed by each individual during each decision event. The assumption is that equal participation, specifically in terms of in contributing one's thoughts or opinions during deliberation, corresponds with equal voice and, therefore, fairness.

The Adjusted Gini Coefficient of Deliberation is computed by taking into account the practical and theoretical consideration that some individuals may not wish to communicate much during deliberation of ideas, yet may still perceive the decision process as fair. This situation is especially commonplace when an individual participates in the final decision by voting or indicating their choice among final options, but does not contribute ideas or opinions for the design and deliberation of those options. Research distinguishing between such "voice" and "choice" aspects of fairness and notes that some individuals prefer not to contribute to deliberation, but instead prefer to exercise choice and, therefore, still feel a sense of procedural fairness and autonomy from contributing to the final decision, especially if they endorse the group's leadership and/or overall decision-making process (de Cremer and Tyler 2005; DeCaro et al. 2015). Thus, an individual may defer deliberation to their fellow group members, and exercise choice when it comes time to choose among the options that have been created. A simple (standard) Gini coefficient may assign too much weight to inequalities produced by individuals who willingly contribute few ideas during deliberation for this specific reason, overestimating perceived inequality (cf. DeCaro \& Stokes, 2013). We therefore calculate an adjusted coefficient that corrects for this potential bias (see calculations below).

\section{Calculations:}

\footnotetext{
${ }^{1}$ Note that Janssen (2010) computed this index on statements (i.e., chat lines), not thought units.
} 
(1) Standard Coefficient. Calculate a Gini Coefficient for each decision event. Use the number of thought units contributed by each individual for each event.

For example, Group 1 had a total of 5 decision events. In Decision 1, Player 1 contributed 1 thought unit, Player 2 contributed 3, Player 3 contributed 3, and Player 4 contributed 6, resulting in a Gini $=0.2885$ for Decision 1 .

(2) Adjusted Coefficient. If an individual (a) contributes few thought units to the group's decisions (nominally $1-5$ thoughts, proportionally approximately less than $10 \%$ of the statements), OR (b) none of those statements are proposals that contribute to the substance of deliberation or design of a solution/agreement, AND (c) the individual explicitly states their agreement or endorsement of the group's decision, then this individual is dropped from ALL the counts in Step A, and ALL Gini Coefficients are re-calculated as if that individual does not exist. This procedure assesses the degree of equality among the remaining (i.e., leading) group members who are engaged in the deliberation process of the decision. ${ }^{2}$ Report all such corrections in the data file and published results.

For example, Group 1 had 5 decision events. We omitted Player 1 because across all 5 decisions, Player 1 contributed only 1 thought unit (in Decision 1), and this thought unit was to express agreement with the group's decision to use a private property rule as their primary conservation strategy. The corrected Gini DM $=0.1667$.

(3) Take the average of the Gini coefficients calculated for all of a group's decision events to get the overall score for the group.

For example:

Group 1's Gini DM coefficients were:

Original

Gini DM $1=0.2885$

Gini DM $2=0.5000$

Gini DM $3=0.4167$

Gini DM $4=0.3214$

Gini DM $5=0.3125$

Average $=0.3678$

\section{$\underline{\text { Adjusted }}$}

Gini DM $1=0.1667$

Gini DM $2=0.3333$

Gini DM 3 $=0.2222$

Gini DM $4=0.0952$

Gini DM $5=0.0833$

Average $=0.1801$

\subsubsection{Democratic Decision Making}

The purpose of this sub-step is to identify the extent to which groups made decisions democratically, in terms of sharing important choices (e.g., final decisions about which conservation agreements to use).

After you have identified each decision event, classify each decision event in terms of the decision strategy that the group used. These designations will be used to determine an overall (most frequently used) decision rule for the group (cf. Vollan 2008).

\section{(1) Code each Decision Event:}

\footnotetext{
2 If you wish to test the robustness of this correction, then calculate the Gini Coefficient with and without the adjustment, and note the effects doing so has on important perceptions and outcomes.
} 
Assign a decision strategy code to each individual decision event:

1. Unresolved/Contested Decision. Either the decision is not resolved (no conclusion reached) or is contested (i.e., split 50/50 among two people versus two others).

2. Unilateral Decision. A decision is made by a single individual (i.e., proposed and imposed/chosen by the same single person), without input from others.

3. Majority Decision. The group chooses the proposal that more individuals support. In a four-person group, this will correspond to either (a) three supporters (3/4 choosing) or (b) two supporters (2/4 choosing) with the remaining individuals being split and prefer altogether different options. ${ }^{3}$

4. Consensus/Unanimous Majority Decision. The group does not finalize a decision unless everyone agrees. This strategy will sometimes be synonymous with a unanimous majority vote, where all four players explicitly approve a proposal by vote (4/4 choosing). In other cases, consensus may be indicated or derived from implicit adoption of a proposed choice option, or simple voicing of support.

\section{(2) Identify the Group's Typical Decision-making Strategy:}

After you identify the decision-making strategy used in each decision event, determine the typical type of strategy used by the group. We adapt conventions established by Vollan (2008:568), analyzing the amount of agreement (i.e., support) among group members as a proxy for self-determination. In particular, we use the average number of individuals that support the group's decisions across the total number of decision events. Hence, collective choice is used as an indicator of group self-determination:

1. Assign each decision strategy (and event) a value corresponding to degree of support or unanimity. This method assumes greater fairness and selfdetermination with more unanimous endorsement for a decision:

(0) Unresolved/Uncontested

(1) Unilateral

(2) 2-Person Majority

(3) 3-Person Majority

(4) Consensus/Unanimous

2. Calculate the average of these values across the group's decision events. For example, Group 1:

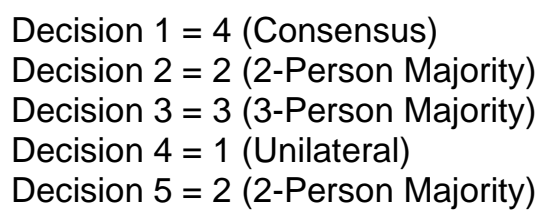

Average $=2.40$

\footnotetext{
${ }^{3}$ Minimal Winning Coalitions: In a small group, it is possible for two members to form a coalition that consistently dominates the other members. This situation is most likely if two group members team up against two disorganized members. Such a situation would not be considered a fully participatory process (unless explicitly endorsed by the minority members). Take note of any minimal winning coalitions that form, and consider analyzing as a moderating factor.
} 


\subsection{INTRODUCTION}

Groups need ways to compel group members to adhere to their agreements. Enforcement is a centrally important activity of governance in a resource dilemma (Ostrom 1990). The effects of various types of enforcement on cooperation, whether positive reinforcement (e.g., praise, encouragement) or negative punishment (e.g., shame, penalties), are debated (see Bowles 2008; DeCaro et al. 2015 for review). The purpose of this coding step is to identify the enforcement methods used by group members to compel each other to comply with the group's rules, strategies, or agreements, in order to facilitate their empirical analysis.

When groups communicate but are unable to use tangible, economic sanctions or other incentive- or economic-based penalties to prevent defection or punish uncooperative behavior, then individuals will primarily rely on social sanctions (cf. Ostrom 1990, Janssen et al. 2010). We distinguish between positive social sanctions (e.g., praise), which encourage and reward cooperation, and negative social sanctions (e.g., shaming, warnings, threats), which seek to discourage defection through verbal penalties, shame, and other negative forms of reinforcement. In some cases, group members may devise ways to coordinate their harvests, specifically to target and reduce the earnings of another group member, or multiple group members, creating a more tangible economic penalty for defection. For simplicity, we include this latter form of tangible, negative sanction with negative social sanctions. ${ }^{4}$

We identify 8 social sanctions (types of enforcement):

1. Acknowledge self or other's cooperation.

2. Praise, Celebrate, or Encourage cooperation.

(positive)

(positive)

3. Request cooperation.

4. Tell someone to cooperate.

(negative)

5. Shame someone for not cooperating.

(negative)

(negative)

6. Warn someone to cooperate.

(negative)

7. Threaten someone to cooperate.

(negative)

8. Punish someone for not cooperating.

(negative)

\section{Distinguishing Enforcement from Goals and Proposals:}

Enforcement statements (technically, thought units) can sometimes be confused with goals and proposals (e.g., proposed solutions). In order for a thought unit to count as enforcement, there must first be either (a) a shared agreement (i.e., a previously chosen proposal, resource management strategy) to enforce or (b) a reasonable expectation (common understanding/norm) that individuals ought to behave in a particular way, with respect to the resource or each other. If neither prerequisite has been met, then the statement is most likely either a goal or a proposal, not enforcement.

\footnotetext{
${ }^{4}$ Another reason for including coordinated punishment with verbal/social negative sanctions is because this type of sanctioning appears to be rare in communication-only lab experiments. The rarity of coordinated punishment is likely due to the fact that this type of enforcement is more complex than, for example, simply verbally shaming a defector, because it requires coordination among multiple individuals. In addition, individuals (in our samples) arguably have more experience using social sanctions on others, not economic sanctions (which is typically left to governments and actors in position of authority, e.g., law enforcement).
} 
Thus, most thought units that look like enforcement when group members first start to communicate are most likely goals or proposals. And, these goals and proposals must be converted to agreements before they can be "enforced."

The main exception to this guideline pertains to Shaming and Threats: individuals may logically try to shame or threaten others to share tokens more equally before a specific solution has been proposed, because equal sharing of tokens (i.e., equity) is a common norm.

\subsection{CATEGORIES AND DEFINTIONS:}

\subsubsection{Acknowledge [ACK]}

Statements where someone either (a) announces or acknowledges their own cooperative behavior or (b) acknowledges another player's cooperation.

\section{Example: Group 14}

Player 1: let's not be betraying each other up in here [WARN]

Player 2: you have my word $[A C K]$

Player 4: right $[A C K]$ we're just all out here tryna get paid $[R A T+]$

Player 1: pinky swear everyone? [REQ]

Player 4: pinky promise!!!!!! [ACK]

Player 3: pinky promise $[A C K]$

Player 2: pinky promise [ACK]

Player 1: pinky promise $[A C K]$

Note: Higher forms of enforcement (e.g., praise, warn) trump Acknowledgement. Thus, if a statement appears to acknowledge cooperation but also includes praise, shame, etc., then use the most appropriate higher type of enforcement code.

\subsubsection{Praise and Encouragement [PRAISE]}

Thought units that: (a) complement someone for perceived good cooperation or compliance, (b) celebrate good performance or cooperation/compliance, or (b) positively/supportively encourage future cooperation, or success.

Praise/Encouragement can come before or after the actual cooperation. For example, group members may praise someone for cooperating. They may also encourage each other to follow a new agreement before the next round begins (i.e., before they have the opportunity to cooperate).

\section{Examples}

- Praise (rewarding observed cooperation):

- "We did good!" [praise/celebration]

- "Good job Player 1!" [praise/compliment]

- Encouragement (encouraging future cooperation):

After Group 16 decided on a conservation agreement, Player 3 said, "lets go team," just before the next round started, encouraging everyone to cooperate with the plan. 
- Encouragement (encouraging future success):

Group 2 established a private property agreement. Player 1 was struggling to "farm" his/her plot effectively, and the following encouragement occurred.

\begin{tabular}{|c|c|c|c|}
\hline 49 & -253.663 & 2 & 1 is just laughing at us now_-_ \\
\hline 50 & -242.727 & 1 & im not \\
\hline 51 & -241.862 & 4 & sorry 1 \\
\hline 52 & -234.344 & 1 & you gus got more than me \\
\hline 53 & -230.886 & 4 & youre the hero to this story (encourage) \\
\hline 54 & -216.773 & 1 & when i try to grow thm they dont work for some reason \\
\hline 55 & -209.635 & 2 & we have to take the middle of the group \\
\hline 56 & -204.542 & 4 & $\begin{array}{l}\text { this is your plot, } 1 \text {, youre the underdog this is your } \\
\text { come up (encourage) }\end{array}$ \\
\hline 69 & -309.272 & 2 & 1 you killed it (praise) \\
\hline 70 & -305.587 & 4 & that was pr solid (praise) \\
\hline 71 & -298.75 & 1 & thanks \\
\hline 72 & -291.612 & 4 & the come up (encourage) \\
\hline 73 & -269.078 & 2 & the come back? (encourage) \\
\hline 74 & -259.433 & 4 & its 1s come up (encourage) \\
\hline 75 & -254.704 & 2 & *insert thinking face emoji* \\
\hline 76 & $241.899 \quad 4$ & im & dcore rooting for 1 (encourage) \\
\hline
\end{tabular}

\subsubsection{Request [REQ]}

Thought units that solicit (ask, request) cooperation, compliance, or commitment to an individual or group solution (e.g., rule, agreement, strategy, or norm). The request can target one or more people.

Examples:

- When an agreement was formed Player 1 (Group 14) asked: "pinky swear everyone?" [REQ]

- Group 24, Player 2: can we please not descend into chaos

\subsubsection{Tell [TELL]}

Thought units in which a person tells one or more group members to cooperate, or to do a specific act that amounts to cooperation/compliance. For these statements to count as Tell, they must be a directive or regulatory statement.

\section{Examples:}

(Group 16)

Group 16 established an agreement where players were supposed to harvest slowly at the beginning of the round, taking only single outlying tokens (tokens not in a cluster), followed by a free-for-all in the last 60 seconds. The following enforcement occurred during the first Round.

Player 3: we need to let them regenerate faster [TELL] [Not a goal, because they had already made an agreement]

Player 4: lets slow down for a bit [TELL] 
Player 3: yes slow down [TELL]

Player 4: one slow down [TELL]

Player 3: theyre about to be gone [WARN]

Player 3: great. [AMBIGUOUS/UNCODEABLE]

Player 2: bro 1 snatched all the tokens [SHAME]

Player 3: exactly...... [SHAME]

Player 1: what? No [SOC INFO]

Player 3: what happened to the waiting plan [SOC INFO] werent we going to wait until the last minute or 30 seconds or something [RULE INFO]

(Group 24)

Player 4: \#1 and \#3: stay in your parts of the board [TELL, private property rule]

\subsubsection{Shame [SHAME]}

Statements/questions in which a person tries to publicly embarrass, guilt, or scold someone for perceived poor cooperation/compliance. This will have a normative (moral) component (e.g., dealing with fairness, moral "right," stealing).

$$
\text { Examples: }
$$

- (Group 21) After trying an agreement:

Player 3: i think that works [PRAISE]

Player 1 : $\mathrm{i}$ think 3 ate them to quick [SHAME]

$\circ \quad($ Group 16)

Player 2: $\quad$ bro 1 snatched all the tokens [SHAME]

Player 3:

exactly...... [SHAME]

Note: If the presumed moral component of the statement is ambiguous (i.e., cannot be determined directly from the statement or indirectly from the context), then consider coding the statement as Acknowledgement or Tell.

\subsubsection{Warn [WARN]}

Statements/questions that warn (i.e., inform) someone about a hypothetical, implied, potential, or actual consequence, retaliation or penalty for failing to cooperate, as a means of preventing future non-cooperation.

\section{Examples:}

○ (Group 1) Player 4: don't come for my crop all i'm saying

○ (Group 24) Player 4: if this devolves into a free-for-all im gonna be pissed.

- (Group 31)

Player 1: NO OFFENSE: BUT 2 you were kinda the problem most of the first rounds. the rest of us were being strategic while the first two rounds you used us and got around 70 tokens each time while the rest of us were in the 30s [SHAME]

Player 3: yes and if you back out of the agreement we're all coming for your coming for your corner in the next rounds [WARM] 
Note about Warn vs. Tell: If in doubt, code as Tell.

Note about Warn vs. Threats: If the "warning" includes cursing or disparaging comments (e.g., calling people names, degrading their intelligence or character), then the statement should be coded as Threaten, not Warn.

\subsubsection{Threaten [THREAT]}

Heated and forceful (hostile) statements/questions used as "weapons" and intended to punish individuals for non-cooperation, or prevent non-cooperation. Threats typically include a warning or penalty statement, but are delivered in a more hostile and extreme tone, with: curses, insults, name-calling or disparaging remarks (e.g: attacks on a person's character). Furthermore, when curses are clearly in response to non-cooperation, treat them as threats.

Examples:

(Group 3) Player 4: \#2 gtfo (get the $f^{\star \star *}$ out))

(Group 33) Player 1: hey 2 go $f^{\star * *}$ yourself. Seriously

(Group 24) Player 4: $f^{\star \star \star}$ ing stop

\subsubsection{Coordinated Punishment [Punish]}

Phrases plus contextual evidence that an individual, or individuals, actuallly retaliate against someone specifically by taking tokens from the other player with the clear (unambiguous) intent to punish or discourage non-cooperation.

If players only have the ability to communicate, and therefore do not have the built-in ability to place monetary sanctions on other players, then Punish will be in the form of strategic taking of tokens understood to be owned/controlled by the targeted player. Thus, in order to be considered PUNISH, there must be evidence in the chat that individuals actually carried out the punishment, otherwise it is mere words and is considered a warning (WARN) or a threat (THREAT). Note: Punishment (Punish) trumps warnings and threats.

- Example of WARN: In Group 31, Players 1, 3, and 4 warned that they would each take tokens from Player 1 if he/she continued to violate the agreement (see Example 3 in the Warn subsection, above). If Players 1, 3, and 4 had actually carried out this punishment (they did not), then their statements would have been coded PUNISH, instead of WARN.

- Example of PUNISH: Based on context, the bolded excerpts below are coded as PUNISH, in Group 40:

During Round 5, Player 1 violated the group agreement:

Player 3: next roumd we takin everything from 1 [WARN]

Player 1: ha goodluck [DEFECT]

Before Round 6, the group had the opportunity to communicate for 5 minutes. Player 1 continued to defy the agreement and taunted the other players about it. Player 4 warned Player 1 of a potential punishment: 
Player 4: 1 aint gon learn, might as well WILD [i.e., go wild] [WARN]

During Round 6, Player 4 and Player 2 took as many tokens as they could from Player 1, carrying out Player 3 and 4's proposed punishment. This action resulted in Player 1 getting less tokens, and equalized the share of tokens among the players:

$\begin{array}{ll}\text { Player } 3 & \text { damnnnn [MON EARNINGS, notices tokens being taken] } \\ \text { Player 1 } & \text { wow okay try hard [DEFECT, POLITE-, retaliates with an insult] } \\ \text { Player } 3 & \text { how did that happen lol [SOC INFO] } \\ \text { Player } 1 & \text { this was pretty even [MON EARNINGS] } \\ \text { Player 2 } & \text { THIS IS WHY CAPITALISM here dont work boi [PUNISH] } \\ \text { Player 4 } & \text { HOW ARE WE MORE EVEN [SOC INFO, MON EARNINGS] } \\ \text { Player 1 } & \text { idk 4 has been ass the whole time [DEFECT, POLITE-] } \\ \text { Player 4 } & \text { im S H O O K E T H [PUNISH, celebrating/gloating] } \\ \text { Player 1 } & \text { you stilll get last place but atleast you got more than 10 [MON } \\ & \text { EARNINGS, POLITE-] } \\ \text { Player } 4 & \text { i dont know i mean i pulled up on ya [PUNISH] }\end{array}$

\subsection{SCORING}

When scoring sanctions as a functional category (enforcement), the objective is to calculate the extent that a group relies on particular methods of enforcement. Thus, the following steps calculate enforcement scores as percentage usage out of the total number of enforcement instances within each group.

(1) Identify the Enforcement Events. An enforcement event occurs whenever_an individual uses one of the listed enforcement methods: a single thought unit counts as an enforcement event. Record the line number associated with each such statement/event for easy reference.

(2) Percentage Use: Count the number of times (thought units) that a particular method is used, and then calculate the percentage each is used out of the total number of enforcement events (i.e., out of $100 \%$ ).

Example: Coding and Scoring Enforcement, Group 1

\begin{tabular}{|l|l|c|}
\hline Code & \multicolumn{1}{|c|}{ Thoughts } & Count (\%) \\
\hline Acknowledge & (L77) Player 3: “Trying to grow that good kush" & $1(11.11 \%)$ \\
\hline Praise/Encourage & (L47) Player 2: “we did good” & $3(33.33 \%)$ \\
\hline & (L49) Player 3: “good work guys” & \\
\hline & (L78) Player 2: “you right” (responding to Player 3 @ L77) & \\
\hline Request & $\begin{array}{l}\text { (L17) Player 4: “but everyone got that? with the whole we } \\
\text { all get our own quadrant thing?” }\end{array}$ & $1(11.11 \%)$ \\
\hline Tell & (L48) Player 4: “don't change” & $2(22.22 \%)$ \\
\hline Shame & (L79) Player 4: "same areas” & $0(0 \%)$ \\
\hline Warn & & $2(22.22 \%)$ \\
\hline & (L41) Player 4: “play nice” & \\
\hline Threaten & (L67) Player 4: “don't come for my crop all i'm saying” & $0(0 \%)$ \\
\hline Punish & & $0(0 \%)$ \\
\hline
\end{tabular}




\subsection{INTRODUCTION}

In this section each thought unit is coded individually, and the frequency (proportion) of different content is determined. Such root frequencies do not necessarily capture the full intent or function contained in dialogue, because they dissect larger segments of dialogue into fragments. However, this coding serves as both a basic descriptor of communication patterns, and as a potentially basic predictor for cooperation in later phases of the experiment. To improve accuracy, we recommend coding root frequencies last, because coders better understand the context of each statement after having read and coded the entire communication session for functional significance (Brauner 2008).

\section{UNIT OF ANALYSIS}

Here, the unit of analysis is the Phrase (a part of a Thought Unit). ${ }^{5}$ There may be multiple phrases in a single Thought Unit.

(1) All phrases must be coded at least once.

(2) Moreover, the scope of coding is more narrow here: each phrase should be coded with regard to its primary content, or intent (Brauner 2018, Tschan et al. 2018).

\section{Additional Guidelines}

A. Some thought units contain multiple ideas (i.e., phrases) or intents: each phrase (or apparent intent) of a complex thought unit should be coded.

B. Most phrases will receive only one code, because they communicate only one thought or idea, or serve only one apparent purpose/intent.

C. Some phrases will receive multiple codes: Phrases may receive multiple codes when necessary, when such a phrase serves more than one function equally. This is especially likely with some particular coding categories:

- Rationales often co-occur with other content to support a thought (e.g., justification for a proposed solution).

- Ecological Information (and other information categories) often co-occur with proposals, enforcement, and other thought units, as a type of rationale (e.g., justifying a proposed solution with an ecological rationale).

D. Simple Replies: Individuals sometimes respond to someone else's statements (thought units) with a simple reply or conversational convention, which indicates acknowledgement and/or agreement (e.g., repeating/reiterating what the other person said, saying "yeah" to confirm shared information, etc.). Unless context suggests otherwise, code these replies using the same code as the thought unit of the original statement.

We provide additional guidance below, in the individual code definitions, when needed to clarify common constraints or special considerations.

\footnotetext{
${ }^{5}$ Standard definition of a "phrase": a small group of words standing together as a conceptual unit.
} 


\subsection{CATEGORIES AND DEFINITIONS}

\subsubsection{Goal [GOAL]}

Discuss goals. Phrases that introduce, ask, or discuss a goal (e.g., purpose, desired achievement, or aim). Goals are general (e.g., let's make the tokens last longer), versus proposals (see the Proposal coding category), which are specific (e.g., let's go slower so we can make the tokens last longer). Goals specify aims or outcomes, not the specific steps, solutions, or methods of obtaining those aims/outcomes. Some common goals: making the tokens last longer, earning more money, egalitarianism (equal sharing of tokens).

Examples:

"Are we supposed to share the tokens? or like see who can get them to fastest?"

"We should make the tokens last longer."

"The point isn't to end with the same amount \{of money/tokens\}, its to make the round last as long as possible" (Debating goals).

\subsubsection{Proposal [PROPOSE]:}

Phrases that introduce (i.e., propose) a new (or not yet resolved). solution. The solution must be a specific strategy, rule, or agreement to improve resource management and/or cooperation: the solution must indicate tangible actions for individuals to take.

\section{Proposals vs. Enforcement:}

Context and timing matters when identifying proposals and distinguishing them from enforcement (especially the enforcement category Tell). Thoughts units about courses of action individuals should take to manage the resource (or solve any other aspect of the socialecological dilemma) must be novel (or not yet resolved) to be considered a proposal. In contrast, if a solution (e.g., conservation agreement) has already been established by the group, thought units that may otherwise seem like a proposal are very likely a form of enforcement, such as encouraging or urging fellow group members to comply with the agreement (i.e., Praise/Encouragement, or Tell forms of enforcement).

Examples:

- "We all get our own quadrant"* [referring to a private property rule]

- "Eat the tokens more slowly"* [referring to a slow harvesting rule]

*These two thought units would be coded as proposals [PROPOSE], if the solutions discussed in the statements have not already been decided/established by the group. However, these two thought units would be coded as a form of enforcement [TELL, Enforcement] if such solutions have been established already.

\section{Proposals vs. Goals:}

Goals are more general than proposals and do not specify specific actions for individuals to take. If a thought unit appears to be a proposal but is stated generally, then it may be a goal. 


\subsubsection{Choosing [CHOOSE+]}

Affirmative or confirmatory phrases central to the act of choosing/selecting a course of action, which indicate selection/support of a choice option. This is not the discussion of those courses of action: this is the actual act of choosing (e.g., votes cast).

Example:

- "But everyone got that? We get our own quadrant?" (Player 4) [PROPOSE] "Yeah" (Player 1) [CHOOSE]

"Yea yea" (Player 2) [CHOOSE]

"Sure" (Player 3) [CHOOSE]

"Good" (Player 4) [CHOOSE]

\section{Implied Choosing:}

Sometimes an individual will not directly voice a choice but will instead move forward with a proposal, indicating assumed/implied choice.

For instance, in the example above, instead of directly voicing his/her choice, Player 3 could have said, "'ll take the top left corner," which indicates preference/choosing of the private property proposal. Such instances should be coded CHOOSE [and RULE INFO].

\subsubsection{Not Choosing/Choosing Against [CHOOSE-]:}

Clear and active disconfirmatory phrases of choice, indicating rejection of a particular choice option. (This does NOT INCLUDE the mere absence of confirmation, so failure to voice support for a particular choice option does NOT count here).

For example:

- Player 2: "PLAN IS 20 SECOND TRUCE" [PROPOSE] Player 1: "That doesnt work" [CHOOSE-]

\subsubsection{Ecological Information [ECO INFO]}

Sharing or discussing ecological information. Information-seeking (or information-providing) phrases that introduce, exchange, or ask for information about the nature of the resource system itself, regardless of accuracy. The statement is used/intended to provide information, or is seeking to understand something about, the ecology of the token resource system. This also includes sharing information about the effects of one's harvesting strategy on token ecology. Some common ecological topics: scarcity, regeneration/regrowth, token locations and distributions, token density, dynamics.

\section{Examples:}

"The whole grid is $413 \times 13$ squares"

"Slow down [PROPOSAL] the tokens replenish [ECO INFO]"

Player 4: "1 how you collect so many. I tried the spacing out thing." Player 1: "that's all that i have been doing, just spacing and timing." 


\subsubsection{Rule Information [RULE INFO]}

Phrases that ask or provide information about the group's chosen (or proposed) agreement(s) specifically for clarification. For example, asking for clarification about whether the agreement is to wait for 30 seconds or 45 seconds before starting to harvest or informing group members of their corner assignment in a private property arrangement.

\section{Proposals vs. Rule Information:}

Unless the context suggests otherwise, the first time information about a rule, strategy, or agreement is stated that thought unit should typically be coded as a proposal (not rule information), because the goal of the thought is to inform the group of a new solution, not clarify an existing solution or a solution idea that has already been posed to the group for consideration. After a proposal has been accepted by the group, information about the rule will typically be considered Rule Information (or possibly a form of Enforcement).

\section{EXAMPLE: DISTINGUISHING RULE INFO FROM A PROPOSAL}

(Group 1)

The group first establishes a private property agreement, then clarifies it.

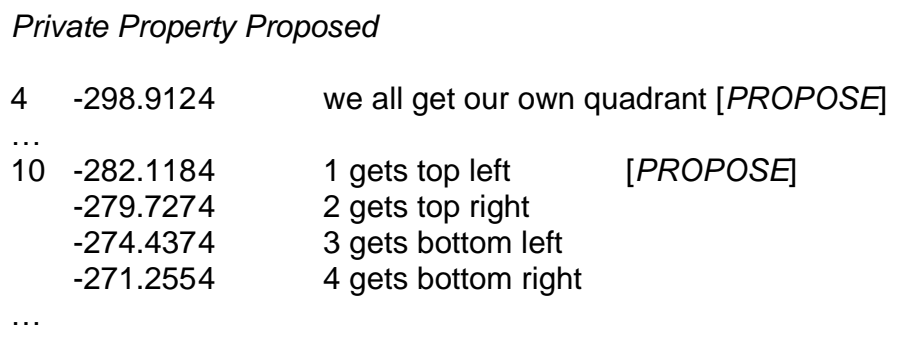

Private Property Arrangements Clarified

$\begin{array}{lll}37-66.253 & 4 & \text { ok so to review } \\ -63.653 & 4 & \text { 1 is top left } \\ -61.417 & 4 & \text { 2 top right } \\ -58.994 & 4 & \text { 3 bottom left } \\ -54.588 & 4 & \mathbf{4} \text { bottom right }\end{array}$

\section{Social Information vs. Rule Info:}

RULE INFO is different from SOC INFO, because SOC INFO asks clarification about motives, beliefs, social dynamics, or behavior. For example, if someone says the group should not do a "free for all" at the end of the round, because it may encourage some group members to collect their own tokens faster (so they can take more tokens from the other Players later during the free for all), then this would be considered sharing social information about the consequences of using a particular agreement (not clarifying the agreement). 


\subsubsection{Social Information [SOC INFO]}

Information-seeking (or information-providing) phrases that introduce, exchange, or ask for information about (a) the social dynamics of the dilemma (i.e., social dilemma) or (b) people's beliefs and motivations, which drive behavior in the dilemma. This includes discussing one's own beliefs/motivations, or discussing other people's.

Common topics (thought units about):

(a) Interdependency (people's behaviors affect one another)

(b) Self-Interest/Competition (the situation tempts people to be greedy or selfish, or to compete with one another)

(c) Tragedy (if people behave selfishly without limit then everyone will suffer)

(d) Motivations (incentive structures, motives, attributions/reasons for behavior).

Examples:

- "If we say it's a free for all at 10 seconds [PROPOSAL] that encourages people to finish early and start sharking" [SOC INFO, competition, motivation]

- Player 2: "1 is just laughing at us now _-_" [SOC INFO, attribution for behavior]. Player 1: "I'm not" [SOC INFO, attribution for own behavior]

○ "I'm broke. I need the money" [incentive structures/motivation]

\subsubsection{Experiment Information [EXP INFO]}

Discussing information about the experiment itself (e.g., experimental design) that is relevant to the focal dilemma task. Information-seeking (or information-providing) phrases that introduce, exchange, or ask for information about aspects of the experiment rules or design that are relevant to and may therefore affect group motivations and decisions: higher order "rules of the game" (e.g.: task instructions) and design constraints (e.g.. number of rounds, length of rounds) that shape and constrain allowable actions and, therefore, motivations and behavior in the focal dilemma task (i.e. game).

\section{Experiment Info vs. Small Talk:}

Statements that talk about the experiment, but do not share information relevant to the fundamental rules of the game or design constraints that directly affect motivations and decisions within the game should be coded as Small Talk.

Examples:

$\circ \quad$ (Group 2)

While finalizing (choosing and specifying) a private property agreement, Player 4 interjects to let the group know that the experiment is designed such that each person starts in their own location on the screen, at the beginning of each round in the token task (thus providing information about the experiment that effects decisions within the game).

Player 3 How about we each pick a corner? [PROPOSAL]

Player $1 \quad$ But yea pick a corner. i agree [CHOOSE]

Player $2 \quad$ I like that [CHOOSE]

Player $3 \quad$ I'll take the top right coner. *corner [RULE INFO]

Player $4 \quad$ we all start in a different corner [EXP INFO] 
- (Group 3)

After deciding on a conservation agreement, one group member (Player 2), says that they will now start making more money. Another player responds to this statement, thinking that Player 2 has violated one of the instructions of the experiment, which is that participants cannot make monetary deals outside the experiment. The group then discusses this, clarifying the experimental guidelines and in doing so clarifying and affecting the incentive structure, and motivations and decisions, within the group.

\begin{tabular}{|c|c|}
\hline Player 2 & now, we'll make some real money [SOC INFO] \\
\hline Player 4 & *illegal* [EXP INFO] \\
\hline Player 2 & no its not [EXP INFO] \\
\hline Player 2 & we'll farm the real tokens then lol [EXP INFO] \\
\hline Player 4 & thats against the guidelines [EXP INFO] \\
\hline Player 4 & and also i dont care fr [SOC INFO] \\
\hline Player 2 & $\begin{array}{l}\text { no, its not, theres no exchange of money outside experiment } \\
\text { [EXP INFO] }\end{array}$ \\
\hline Player 2 & shit u right [EXP INFO] \\
\hline
\end{tabular}

\subsubsection{Monitor Resource [MONITOR RES]:}

Phrases where the sole purpose is to factually notice and report the status of the resource pool (tokens), WITHOUT judging or evaluating someone's behavior. This category should be strictly distinguished from Enforcement; enforcement trumps monitoring.

Examples:

- "There's a lot of extra tokens" (discussing leftover tokens)

○ "We have 2 tokens left."

\subsubsection{Monitor Earnings [MON EARN]:}

Phrases where the sole purpose is to factually notice and report the status of one's earnings, or someone else's earnings WITHOUT judging or evaluating someone's behavior. Keeping track of economic outcomes or economic productivity. This category should be strictly distinguished from Enforcement; enforcement trumps monitoring.

\subsubsection{Monitor Behavior [MON BEH]:}

Phrases where the sole purpose is to factually notice and report someone's behavior, WITHOUT judging or evaluating that behavior. This category should be strictly distinguished from Enforcement; enforcement trumps monitoring.

Examples:

- "Player 1 left their corner." (In context of private property)

- "Player 1 started a couple seconds early." (In context of a delayed harvest)

\section{NOTE: Enforcement Trumps Monitoring:}

If the statement seems to imply some kind of judgment or evaluation of someone's behavior, carries a moral or normative sentiment or tone, or is used in the same thought unit as enforcement, then code the phrase or statement as the most relevant type of Enforcement. 


\subsubsection{Solicit/Encourage Input [INPUT +]}

Phrases where someone (a) actively solicits input from at least one other individual (e.g., asks for input, feedback), (b) encourages others to contribute to discussion, or (b) protects/defends the right of others to communicate. In some cases, input can be solicited simply by asking a question, or adding a question mark to a thought unit that might otherwise be a proposal or other directive.

Examples:

- "Ok everyone how bout this?" [INPUT+]

- "If there's 10 seconds left and you have a lot of coin thingys, I'll help you clear them out. ;) [PROPOSE] "yea?" [INPUT +]

- "but everyone got that? [INPUT +] with the whole we get our own quadrant thing? [PROPOSE, INPUT +]"

\subsubsection{Discourage Input [INPUT -]}

Phrases where someone actively tries to prevent an individual from contributing to the discussion, or encourages others to ignore particular individuals.

\section{Examples:}

- "Shut up Player 1!"

- "Ignore Player 3."

- "I don't care what you have to say."

\subsubsection{Rationale [RAT +]}

Phrases where someone provides a rationale (reason, justification, explanation) for a goal, proposal, decision, behavior, process, or outcome.

Note: Rationales frequently overlap or co-occur with other kinds of phrases, or thought units (e.g., ECO INFO, PROPOSE).

\section{Examples:}

- "I say stick to your own area no matter what [PROPOSE] be if we say it's a free for all at 10 seconds [PROPSE] that encourages people to finish up early and start sharking [RAT +]."

- "Slow down [PROPOSE], the tokens replenish [RAT +], so it's not a race [GOAL]."

\subsubsection{Rationale Denied [RAT -]}

Phrases where someone actively refuses to provide a rationale or tries to prevent others from providing rationales. Merely failing to provide a rational does NOT count as a deliberate/active attempt to deny a rationale. Only count deliberate/active attempts.

Examples:

- "No. I don't have to explain myself!"

- "We shouldn't even bother explaining ourselves to Player 2." 


\subsubsection{Polite [POLITE +]:}

Phrases in which the primary purpose (content) is to be polite or respectful.

For example: (a) greetings, (b) statements of gratitude (giving thanks), or (c) saying sorry as a gesture of kindness, courtesy (e.g., for accidentally saying inaccurate information), or sympathy (e.g., if something unfortunate happened to someone by a natural occurrence or "act of nature").

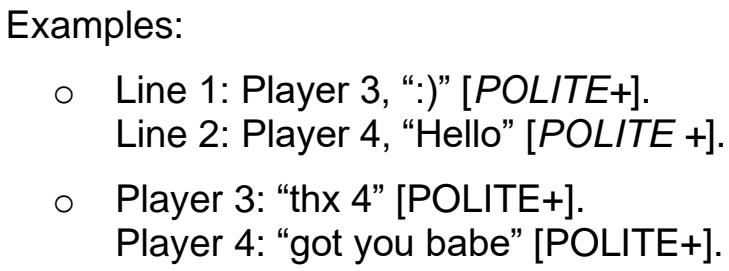

\section{Politeness vs. Enforcement:}

Enforcement codes trump politeness codes. So if a phrase or thought unit contains enforcement, then that phrase or thought unit will NOT be coded as polite. This situation is especially common, with Praise/Encouragement (see Enforcement).

\section{Politeness vs. Restorative Justice (Apologies, Atonement, etc.):}

Restorative Justice codes trump politeness codes. So if a phrase or thought unit's context indicates that a person is apologizing, atoning for, or explaining/justifying a perceived harm or wrong (to ameliorate the harm/wrong), even though you might at first glance consider this an act of politeness, it is more useful to distinguish the act based on its primary intent, which is some form of restorative justice. Hence, such situations will be coded as restorative justice acts (e.g., apologies).

\subsubsection{Impolite [POLITE -]}

Phrases where the primary purpose (content) is to actively behave in an impolite or discourteous way, or disrespect someone. This includes intentional rude interruptions, actively refusing to give thanks, name calling, etc.

Example (Impolite):

- Player 3: "So how is everyone" [POLITE+].

Player 4: "nahhhhh" [POLITE-]

Player 3 tries to start small talk, and Player 4 immediately and impolitely shuts the conversation down, dismissing it outright.

\section{*Impoliteness [POLITE - ] is trumped by Enforcement, Restorative Justice, and other primary codes.}

Example (Enforcement and Restorative Justice Trump Impoliteness):

Player 4 (L84): "2 you made me really made cuz $u$ took all the tokens at first" [POSE HARM] "I was trying to be equal" [RAT+]

Player 2 (L86): "not really I was working in one quadrant" [RJ+ Justify] 
Player 4 (L87): "but no one else knew that" [SHAME]

Player 2 (L88): "I was like these [tokens] are mines" [RJ+ Justify]

Player 4 (L89): "tf you mean? we couldn't talk how were we supposed to know" [SHAME, RJ+ Justify]

\subsubsection{Perceived Harm [POSE HARM]}

Phrases where someone raises a perceived harm/injustice for a particular individual, or the entire group, to consider. Frequently, these will trigger a Restorative Justice Event.

For example:

- Player 3 (Group 1): "also y'all took my tokens i had"

- Player 4 (Group 2): "2 you made me really mad cuz u took all the tokens at first" "i was trying to be equal"

\subsubsection{Concern [POSE CONCERN]}

Phrases where someone raises a non-harm related (see POSE HARM) concern or problem for an individual or the group to consider. Frequently, these will trigger a Decision Event, in order to discuss a potential solution (e.g., modification of an existing strategy or agreement to correct the concern).

For example:

(Group 1)

Player 2: "If there's 10 seconds left and you have a lot of coin thingys, I'Il help you clear them out. ;)" [PROPOSE]

Player 2: "yea?" [INPUT+]

Player 4: "i say stick to your own area no matter what" [PROPOSE]

Player 2 "But then there's a lot extra." [POSE CONCERN, RAT+]

\section{Pose Concern vs. Pose Harm, Goals, and Proposals:}

Unless context suggests otherwise, goals, proposals, and posed harms (i.e., perceived injustices) all trump potential Pose Concern codes. Thus, if a potential concern could possibly be coded as a goal, proposal, or posed harm, then code it as such.

\subsubsection{Apology, Atone, Justify}

Note: The following codes pertain to situations where someone is actively trying to restore justice after a perceived wrong/injustice. Thus, in order for any of these codes to be applicable, there typically must first be an accusation or claim of harm/injustice (i.e., POSE CONCERN).

(a) Apology [RJ + APOLOGY]: apologizes for a perceived harm/injustice (i.e., acknowledges fault and is remorseful) 
(b) Atone [RJ + ATONE]: atones for a perceived harm/injustice by correcting the wrong or making amends (e.g., agreeing to allow a player to take some tokens from one's own available resource pool to make up for taking tokens from that player's pool).

(c) Justify (RJ + JUSTIFY]: provides a rationale that is unambiguously intended to justify their behavior or attempts to explain the situation (i.e., root cause) of the problem [JUSTIFY]

Special Consideration: As with any other simple reply, forgiveness and acceptance of an apology/atonement counts as those forms of restorative justice.

\subsubsection{Restore Justice- [RJ-]}

A player actively refuses to (a) apologize, (b) justify their behavior/explain the root cause of the problem, or (c) atone/make amends. Mere failure (i.e., omission) to apologize, justify, or atone is ambiguous in its intent and therefore should NOT be coded as un-restorative. Actively refusing to forgive, or to accept an apology/atonement, also counts as RJ-.

Special Note: We distinguish between 3 different types of restorative justice (apologies, atonement, and justification, see Restorative Justice above). But we do not distinguish between different types of lack of restorative justice, because these often cannot be clearly distinguished. In other words, it is fairly easy to identify when someone has apologized, versus made atonement, versus justified a wrong (because it is a clear act). In contrast, it is often not easy or possible to identify when a person has refused to specifically apologize, versus make atonement, versus justify the wrong because the absence of a specific act is more difficult to detect than the presence.

\subsubsection{Small Talk [SM TALK]}

Off-task statements, not directly related to the token task. For example, sharing or discussing personal interests, popular events or topics (e.g., movies, school), and personal information (self-disclosure) (e.g., personal experiences, intimacies). Include both active (e.g., raising a topic) and passive comments (replies).

\section{Exclude statements clearly intended as humor (see Humor below).}

\subsubsection{Humor [HUMOR]}

Obvious and intentional attempts to amuse another person. Here, code as humor only if humor is the sole/primary.purpose of the statement: e.g., jokes, silly statements, and unexpectedly odd statements.

\subsubsection{Enforcement}

Coding: The codes assigned for enforcement are identical to those discussed earlier, in the Compel and Sustain Cooperation (Enforcement) section of this codebook. Refer to that section for coding definitions and guidelines.

- Acknowledge someone's cooperation, without praise. 
- Praise, Celebrate, or Encourage cooperation.

- Request cooperation.

[PRAISE]

- Tell others to cooperate.

[REQ]

[TELL]

- Shame someone for not cooperating.

[SHAME]

- Warn someone to cooperate, including consequence

[WARN]

- Threaten someone to cooperate (Warn + hostile)

[THREAT]

- Punish someone with tangible penalty (trumps Threat)

\subsubsection{Defection [DEFECT]}

Phrases that either directly communicate or exhibit (i.e., amount to) a deliberate act of defection or defiance of a group's rule/strategy/norm. This includes taunts.

For example: (Group 41): Stated in the context of repeated agreement violations:

Player 4: "1 you still greedy" [SHAME]

Player 1: "lol" [DEFECT]

Player 3: "I look over and you acting wild @1" [SHAME]

Player 1: "get rekd XD" [DEFECT]

....

Player 1: "L" [types "L", meaning “Losers," repeatedly] [DEFECT]

Player 1: "im going ballsdeep next round just a warning" [DEFECT]

Player 1: "goodluck" [DEFECT]

\subsubsection{Ambiguous [AMB]}

Phrases where the purpose/intent or meaning of the content is unclear, or that may fall into a particular category but are unclear (i.e., coding will be unreliable).

\subsubsection{Uncodable [UNCODE]}

Phrases for which there is no established code, or the chat text is undecipherable.

If there is no existing code, then consider making a new code to capture the content. 


\section{REFERENCES}

Bowles, S. (2008). Policies designed for self-interested citizens may undermine "the moral sentiments": evidence from economic experiments. Science, 320, 1605-1609

Brauner, E. 2018. Coding interaction: a technical introduction. Pages 165-190 in E. Brauner, M. Boos, and M. Kolke (Eds), The Cambridge Book of Group Interaction Analysis. Cambridge University Press, USA.

Colquitt, J. A. (2001). On the dimensionality of organizational justice: a construct validation of a measure. Journal of Applied Psychology, 86(3), 386-400.

Coupland, J., 2003. Small talk: Social functions. Research on Language and Social Interaction, 36(1), pp.1-6.

De Boni, M., Richardson, A. and Hurling, R., 2008. Humour, Relationship Maintenance and Personality Matching in automated dialogue: A controlled study. Interacting with Computers, 20(3), 342-353.

De Cremer, D., \& Tyler, T. R. (2005). Managing group behavior: the interplay between procedural justice, sense of self, and cooperation. Advances in Experimental Social Psychology, 37, 151-218.

DeCaro, D. A. (2019). Humanistic rational choice: understanding the fundamental motivations that drive self-organization and cooperation in commons dilemmas. (Pages 117-131). In B. Hudson., J.

Rosenbloom, \& D. Cole (Eds), Routledge Handbook of the Study of the Commons. Routledge, New York, USA.

DeCaro, D. A. (2011). Considering a broader view of power, participation, and social justice in the Ostrom Institutional Analysis Framework. Grassroots Economic Organizing Newsletter, 2(9).

http://geo.coop/node/651

DeCaro, D. A., Janssen, M. A., \& Lee, A. (with Ostrom, E). (2015). Synergistic effects of voting and enforcement on internalized motivation to cooperate in a resource dilemma. Judgment and Decision Making, 10(6), 511-537.

DeCaro, D. A., \& Stokes, M. K. (2013). Public participation and institutional fit: a social-psychological perspective. Ecology and Society, 18(4), 40. http://dx.doi.org/10.5751/ES-05837-180440

Deci, E. L., and Ryan, R.M. (1987). The support of autonomy and the control of behavior. Journal of Personality and Social Psychology, 53(4), 1024-1037.

Deci, E. L., \& Ryan, R. M. (2000). The "what" and "why" of goal pursuits: human needs and the selfdetermination of behavior. Psychological Inquiry, 11, 227-268.

Eggins, S. and Slade, D., 2005. Analysing casual conversation. Equinox Publishing Ltd.

Frey, B. S., Benz, M., \& Stutzer, A. (2004). Introducing procedural utility. Not only what, but also how matters. Journal of Institutional and Theoretical Economics, 160, 377-401.

Gardner, R., Ostrom, E. and Walker, J.M. (1990). The nature of common-pool resource problems. Rationality and society, 2(3), 335-358.

Greene, J.A., and Azevedo, R. A theoretical review of Winne and Hadwin's model of self-regulated learning: new perspectives and directions. Review of Educational Research, 77(3), 334-372.

Janssen, M. A. (2010). Introducing ecological dynamics into common-pool resource experiments. Ecology 
and Society, 15(2), 7. http://www.ecologyandsociety.org/vot15/iss2/art7/

Lerman, R.I. and Yitzhaki, S. (1984). A note on the calculation and interpretation of the Gini index. Economics Letters, 15(3-4), 363-368.

Ostrom, E. (1990). Governing the Commons: Evolution of Institutions for Collective Action. Cambridge, UK: Cambridge University Press.

Ostrom, E., Walker, J., \& Gardner, R. (1992). Covenants with and without a sword: self-governance is possible. American Political Science Review, 86(2), 404-417.

Ostrom, V., 1980. Hobbes, covenant, and constitution. Publius, 10(4), 83-100.

Ostrom, V. (1994). The Meaning of American Federalism. Constituting a Self-Governing Society. San Francisco: ICS Press.

Pavitt, C., 2011. Communication, performance, and perceptions in experimental simulations of resource dilemmas. Small Group Research, 42(3), 283-308.

Ratajczyk, E., Brady, U., Baggio, J.A., Barnett, A.J., Perez-lbara, I., Rollins, N., Rubiños, C., Shin, H.C., Yu, D.J., Aggarwal, R. and Anderies, J.M. (2016). Challenges and opportunities in coding the commons: Problems, procedures, and potential solutions in large-N comparative case studies. International Journal of the Commons, 10(2), 440-466.

Reed, N., Metzger, Y., Kolbe, M., Zobel, S., and Boos, M. 2018. Unitizing verbal interaction data for coding. (pp. 208-226) In E. Brauner, M. Boos, an M. Kolbe (Eds), The Cambridge Handbook of Group Interaction Analysis. Cambridge University Press, USA.

Rogat, T.K. and Adams-Wiggins, K.R. 2014. Other-regulation in collaborative groups: implications for regulation quality. Instructional Science, 42(6), 879-904.

Ryan, R.M, \& Deci, E.L. (2017). Economic and political systems. In R.M. Ryan \& E.L. Deci (Eds.), SelfDetermination Theory: Basic psychological needs in motivation, development, and wellness (pp. 591615). New York, NY: The Guilford Press.

Tschan, F., Zimmerman, J., Semmer, N. K. (2018). Rules for coding scheme development. Pages $191-$ 2017 in E. Brauner, M. Boos, and M. Kolke (Eds), The Cambridge Book of Group Interaction Analysis. Cambridge University Press, USA.

Tyler, T. R. (1990). Why people obey the law. New Haven, CT: Yale.

Tyler, T. R. (2006). Psychological perspectives on legitimacy and legitimization. Annual Reviews of Psychology, 57, 375-400.

van Prooijen, J. W. (2009). Procedural justice as autonomy regulation. Journal of Personality and Social Psychology, 96(6), 1166-1180.

Vollan, B. (2008). Socio-ecological explanations for crowding out effects from economic field experiments in southern Africa. Ecological Economics, 67, 560-573.

Wittenbaum, G.M., Hubbell, A.P. and Zuckerman, C. (1999). Mutual enhancement: Toward an understanding of the collective preference for shared information. Journal of Personality and Social Psychology, 77(5), 967-978.

Yu, D.J., Shin, H.C., Pérez, I., Anderies, J.M. and Janssen, M.A. (2016). Learning for resilience-based management: Generating hypotheses from a behavioral study. Global environmental change, 37, 69-78. 
